\title{
Activation of Gold on Metal Carbides: Novel Catalysts for C1 Chemistry
}

\author{
José A. Rodriguez * \\ Brookhaven National Laboratory, Department of Chemistry, Upton, NY, United States
}

This article presents a review of recent uses of Au-carbide interfaces as catalysts for $\mathrm{C} 1$ Chemistry ( $\mathrm{CO}$ oxidation, low-temperature water-gas shift, and $\mathrm{CO}_{2}$ hydrogenation). The results of density-functional calculations and photoemission point to important electronic perturbations when small two-dimensional clusters of gold are bounded to the (001) surface of various transition metal carbides (TiC, ZrC, VC, Ta C, and $\delta-M o C$ ). On these surfaces, the $\mathrm{C}$ sites exhibited strong interactions with the gold clusters. On the carbide surfaces, the Au interacts stronger than on oxides opening the door for strong metal-support interactions. So far, most of the experimental studies with well-defined systems have been focused on the $\mathrm{Au} / \mathrm{TiC}, \mathrm{Au} / \delta-\mathrm{MoC}$, and $\mathrm{Au} / \beta-\mathrm{Mo}_{2} \mathrm{C}$ interfaces. $\mathrm{Au} / \mathrm{TiC}$ and $\mathrm{Au} / \delta-\mathrm{MoC}$ are active and stable catalysts for the low-temperature water-gas shift reaction and for the hydrogenation of $\mathrm{CO}_{2}$ to methanol or $\mathrm{CO}$. Variations in the behavior of the $\mathrm{Au} / \delta-\mathrm{MoC}$ and $\mathrm{Au} / \beta-\mathrm{Mo}_{2} \mathrm{C}$ systems clearly show the strong effect of the metal/carbon ratio on the performance of the carbide catalysts. This parameter substantially impacts the chemical behavior of the carbide and its interaction with supported metals, up to the point of modifying the reaction rate and mechanism of

Edited by:

Tomas Ramirez Reina,

University of Surrey, United Kingdom

Reviewed by:

Miguel Angel Centeno,

Instituto de Ciencia de Materiales de

Sevilla (ICMS), Spain

Tatyana Todorova Tabakova,

Institute of Catalysis (BAS), Bulgaria

*Correspondence: José A. Rodriguez rodrigez@onl.gov

Specialty section: This article was submitted to Catalysis and Photocatalysis,

a section of the journal

Frontiers in Chemistry

Received: 11 November 2019 Accepted: 04 December 2019

Published: 08 January 2020

Citation:

Rodriguez JA (2020) Activation of Gold on Metal Carbides: Novel Catalysts for

Keywords: gold, metal carbides, $\mathrm{C} 1$ chemistry, water-gas shift reaction, $\mathrm{CO}_{2}$ hydrogenation

\section{INTRODUCTION}

In the last 15 years, several studies have shown that Au nanoparticles dispersed on carbide surfaces can be very active as catalysts for process related to $\mathrm{C} 1$ chemistry such as the oxidation of carbon monoxide $\left(\mathrm{CO}+0.5 \mathrm{O}_{2} \rightarrow \mathrm{CO}_{2}\right.$ ) (Ono et al., 2006; Rodriguez et al., 2010), the water-gas shift reaction $\left(\mathrm{CO}+\mathrm{H}_{2} \mathrm{O} \rightarrow \mathrm{H}_{2}+\mathrm{CO}_{2}\right.$ ) (Rodriguez et al., 2014; Posada-Perez et al., 2017; Yao et al., 2017), and the hydrogenation of carbon dioxide to methanol $\left(\mathrm{CO}_{2}+3 \mathrm{H}_{2} \rightarrow \mathrm{CH}_{3} \mathrm{OH}+\mathrm{H}_{2} \mathrm{O}\right)$ (Vidal et al., 2012; Rodriguez et al., 2013; Posada-Pérez et al., 2016). It is quite interesting that Au is activated by bonding interactions with carbide substrates. For many years, a lot of attention has been focused on examining the properties of $\mathrm{Au}$ in contact with different types of oxide supports $\left(\mathrm{Al}_{2} \mathrm{O}_{3}, \mathrm{MgO}, \mathrm{CeO}_{2}, \mathrm{TiO}_{2}, \mathrm{InO}_{2}, \mathrm{ZrO}_{2}, \mathrm{CrO}_{\mathrm{x}}, \mathrm{MnO}_{\mathrm{x}}, \mathrm{Fe}_{2} \mathrm{O}_{3}\right)$ (Haruta, 1997; Fu et al., 2003; Campbell, 2004; Zhang et al., 2005; Yang et al., 2013; Gu et al., 2014). Bulk metallic Au displays a low reactivity as a consequence of combining a deep-lying valence $\mathrm{d}$ band and very diffuse valence s, p orbitals (Hammer and Nørskov, 1995). In the literature, the activation of supported gold has been explained using several models: From special chemical properties resulting from the limited size of the active gold particles (usually $<5 \mathrm{~nm}$ ), to the effects of charge transfer between the oxide and gold. What happens when gold is dispersed on a substrate which has physical and chemical properties different from those typical of an oxide? The carbides of the early-transition metals have a much lower ionicity than typical oxides and exhibit, in many aspects, a chemical behavior similar to that of noble metals (Hwu and Chen, 2005). 
The inclusion of $\mathrm{C}$ into the lattice of an early-transition metal modifies the chemical reactivity of the system through ensemble and ligand effects (Liu and Rodriguez, 2004; Hwu and Chen, 2005; Rodriguez and Illas, 2012). After forming a compound, the presence of the carbon atoms in the lattice puts a limit in the total number of metal atoms that can be present in a surface of a metal carbide (ensemble effect). Furthermore, the formation of metal-carbon bonds perturbs the electronic properties of the metal (reduction in its density of states near the Fermi level; a net metal $\rightarrow$ carbon charge transfer) (Liu and Rodriguez, 2004; Hwu and Chen, 2005), making it less chemically active (ligand effect) and a better catalyst according to the Sabatier's principle (Liu and Rodriguez, 2004). The electron-rich carbon atoms present in carbide surfaces interact well with Au adatoms (Rodriguez and Illas, 2012). A charge polarization induced by $\mathrm{Au} \leftrightarrow \mathrm{C}$ interactions (Figure 1) produces systems which exhibit a chemical activity much larger than those found after the deposition of gold on surfaces of oxides (Rodriguez and Illas, 2012).
In this article, a short review on the uses $\mathrm{Au}$-carbide interfaces in $\mathrm{C} 1$ catalysis is presented. The text is organized as follows. The next section describes studies dealing with $\mathrm{CO}$ oxidation (Ono et al., 2006; Rodriguez et al., 2010). Then, we focus on works examining the water-gas shift reaction (Rodriguez et al., 2014; Posada-Perez et al., 2017; Yao et al., 2017). This is followed by studies on the activation of $\mathrm{CO}_{2}$ and its conversion into $\mathrm{CO}$ or methanol (Vidal et al., 2012; Rodriguez et al., 2013; PosadaPérez et al., 2016). The article ends with a discussion on future directions for the use of $\mathrm{Au}$-carbide interfaces in $\mathrm{C} 1$ catalysis.

\section{CO OXIDATION}

Roldan-Cuenya et al. studied the growth mode of $\mathrm{Au}$ on TiC films using scanning microscopy (STM) (Naitabdi et al., 2006; Ono et al., 2006; Ono and Roldan-Cuenya, 2007). In general, the gold did not wet well the carbide surface. It formed three-dimensional (3D) nanoparticles at medium and large
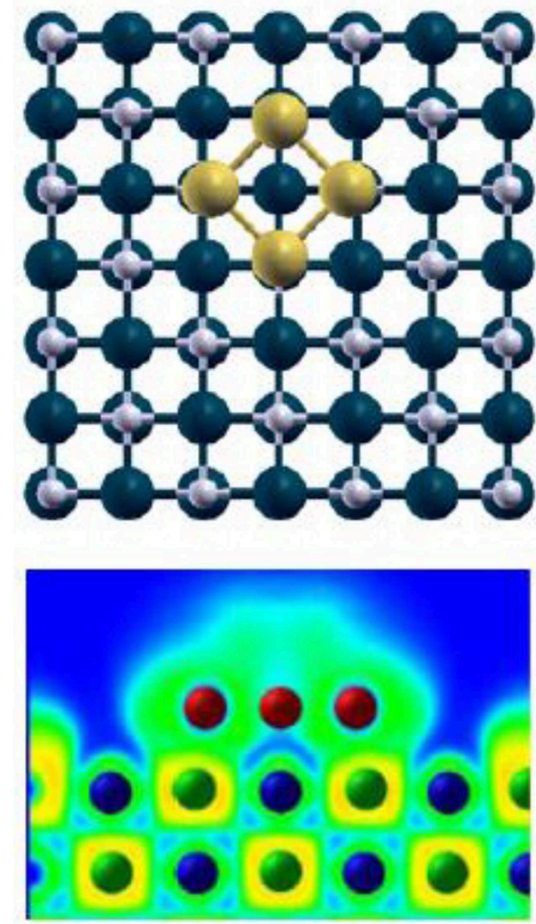

$\mathrm{Au}_{4} / \mathrm{TiC}$
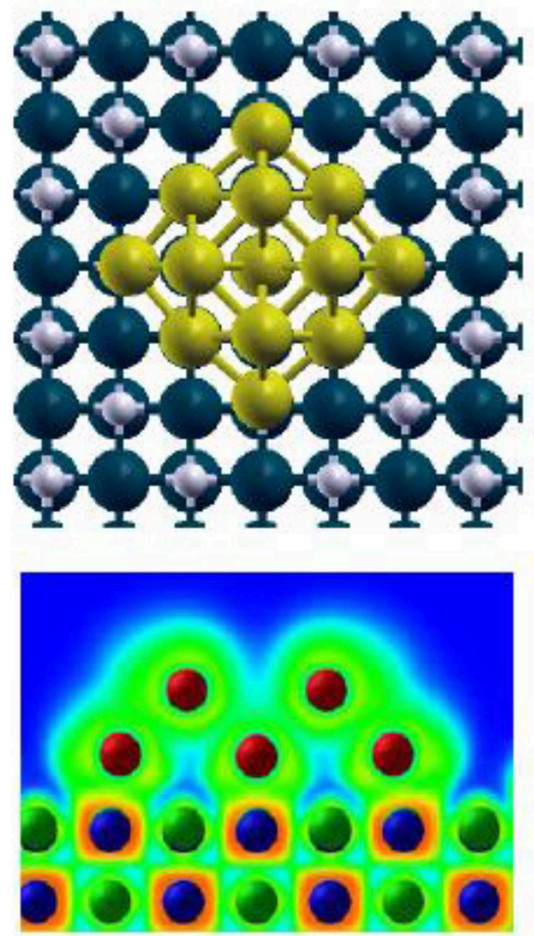

$\mathrm{Au}_{13} / \mathrm{TiC}$

FIGURE 1 | Bonding configurations (top section) and ELF maps (bottom section) calculated for $\mathrm{Au}_{4}$ and $\mathrm{Au}_{13}$ clusters on TiC(001) using DF-based methods. Color code: Carbon atoms are represented by gray spheres, titanium atoms as blue spheres, and gold atoms as yellow spheres. The Au $\mathrm{u}_{13} \mathrm{Cluster}$ contains two layers of 9 and 4 metal atoms. Bottom, ELF maps: The probability of finding an electron varies from 0 (blue color) to 1 (red color). Reproduced with permission from Rodriguez and IIlas (2012), copyright 2012 by the Royal Society of Chemistry. 
coverages. Measurements of scanning tunneling spectroscopy (STS) showed the existence of a band gap for the Au nanoparticles with heights in the range of 1.3 to $2.1 \mathrm{~nm}$. The $\mathrm{Au} / \mathrm{TiC}$ systems were able to perform the low-temperature oxidation of $\mathrm{CO}$ (Ono et al., 2006; Ono and Roldan-Cuenya, 2007). This motivated a detailed study of the interaction of Au with $\mathrm{TiC}(001)$ (Rodriguez et al., 2007). STM images and XPS data for Au on TiC(001) point to a lack of layer-by-layer growth, with the admetal forming $2 \mathrm{D}$ and $3 \mathrm{D}$ islands over the carbide surface (Rodriguez et al., 2007). High-resolution photoemission data point to a strong $\mathrm{Au} \leftrightarrow \mathrm{TiC}(001)$ interaction (Rodriguez et al., 2007). The C 1s photoemission results indicate that Au prefers to interact with the carbon centers of $\mathrm{TiC}(001)$. Density functional (DF) calculations for the bonding of gold atoms and a series of clusters $\left(\mathrm{Au}_{2}\right.$, $\left.\mathrm{Au}_{4}, \mathrm{Au}_{13}, \mathrm{Au}_{29}\right)$ on $\mathrm{TiC}(001)$ also give preferential adsorption on C sites (Rodriguez et al., 2007). Figure 1 shows calculated electron-localization function (ELF) (Silvi and Savin, 1994) plots for clusters of $\mathrm{Au}_{4}$ and $\mathrm{Au}_{13}$ bonded to $\mathrm{TiC}(001)$. For the $\mathrm{Au}_{4} / \mathrm{TiC}(001)$ system, one can see a substantial accumulation of electrons in the region outside the $\mathrm{Au}_{4}$ cluster. A phenomenon which was also seen when $\mathrm{Au}, \mathrm{Au}_{2}$, and other small clusters where deposited on the carbide substrate (Rodriguez et al., 2007). In the case of $\mathrm{Au}_{13} / \mathrm{TiC}(001)$, the gold cluster now has two layers, with gold atoms that are not in contact with the support. These second-layer atoms, as shown in Figure 1, do not exhibit a polarization of electrons as pronounced as found in the case of $\mathrm{Au}_{4} / \mathrm{TiC}(001)$. In fact, for $\mathrm{Au}_{13} / \mathrm{TiC}(001)$, the polarization of electrons in the first layer is minor. The DF results in Figure 1 are consistent with results of photoemission which point to electronic perturbations on gold only at small coverages of the metal (Rodriguez et al., 2007). Theory and experiment show that one really needs small 2D gold clusters in contact with $\mathrm{TiC}(001)$. The results of several theoretical studies dealing with metalcarbide interfaces predict big differences between the chemical reactivity of $2 \mathrm{D}$ and $3 \mathrm{D}$ gold clusters (Zhang et al., 2005). A phenomenon which have been experimentally verified for several catalytic processes (Vidal et al., 2012; Rodriguez et al., 2013, 2014; Posada-Pérez et al., 2016; Posada-Perez et al., 2017; Yao et al., 2017).

Nanoparticles of gold dispersed on $\mathrm{TiC}$ films and $\mathrm{TiC}(001)$ oxidize carbon monoxide $\left(2 \mathrm{CO}+\mathrm{O}_{2} \rightarrow 2 \mathrm{CO}_{2}\right)$ at temperatures below $200 \mathrm{~K}$ (Ono et al., 2006; Rodriguez et al., 2010). Following the coadsorption of $\mathrm{CO}$ and $\mathrm{O}_{2}$ at $\sim 100 \mathrm{~K}$, the evolution of $\mathrm{CO}_{2}$ was detected at $160-180 \mathrm{~K}$ during the ramping up of the temperature (Ono et al., 2006; Rodriguez et al., 2010). Neither pure metallic gold nor regular $\mathrm{TiC}$ promote the low temperature oxidation of CO. Thus, the oxidation of $\mathrm{CO}$ is probably occurring on the small $\mathrm{Au}$ particles or on the gold-carbide interface. DF calculations predict similar adsorption energies for $\mathrm{CO}$ on $\mathrm{TiC}(001)$ and $\mathrm{Au} / \mathrm{TiC}(001)$ surfaces (Rodriguez et al., 2010). Thus, the good performance of the $\mathrm{Au} / \mathrm{TiC}$ system in $\mathrm{CO}$ oxidation must be a direct result of the ability that the $\mathrm{Au}$ in contact with $\mathrm{TiC}$ has to activate the $\mathrm{O}_{2}$ molecule (Rodriguez et al., 2010). The calculated $\mathrm{O}_{2}$ adsorption energy varies from $-0.45 \mathrm{eV}$ on $\mathrm{TiC}(001)$ to $-1.41 \mathrm{eV}$ on $\mathrm{Au}_{4} / \mathrm{TiC}(001)$ (Rodriguez et al., 2010). Furthermore, the O-O bond length rises from $1.23 \AA$ in free $\mathrm{O}_{2}$ to $1.55 \AA$ in adsorbed $\mathrm{O}_{2}$. On $\mathrm{Au}_{4} / \mathrm{TiC}(001)$,
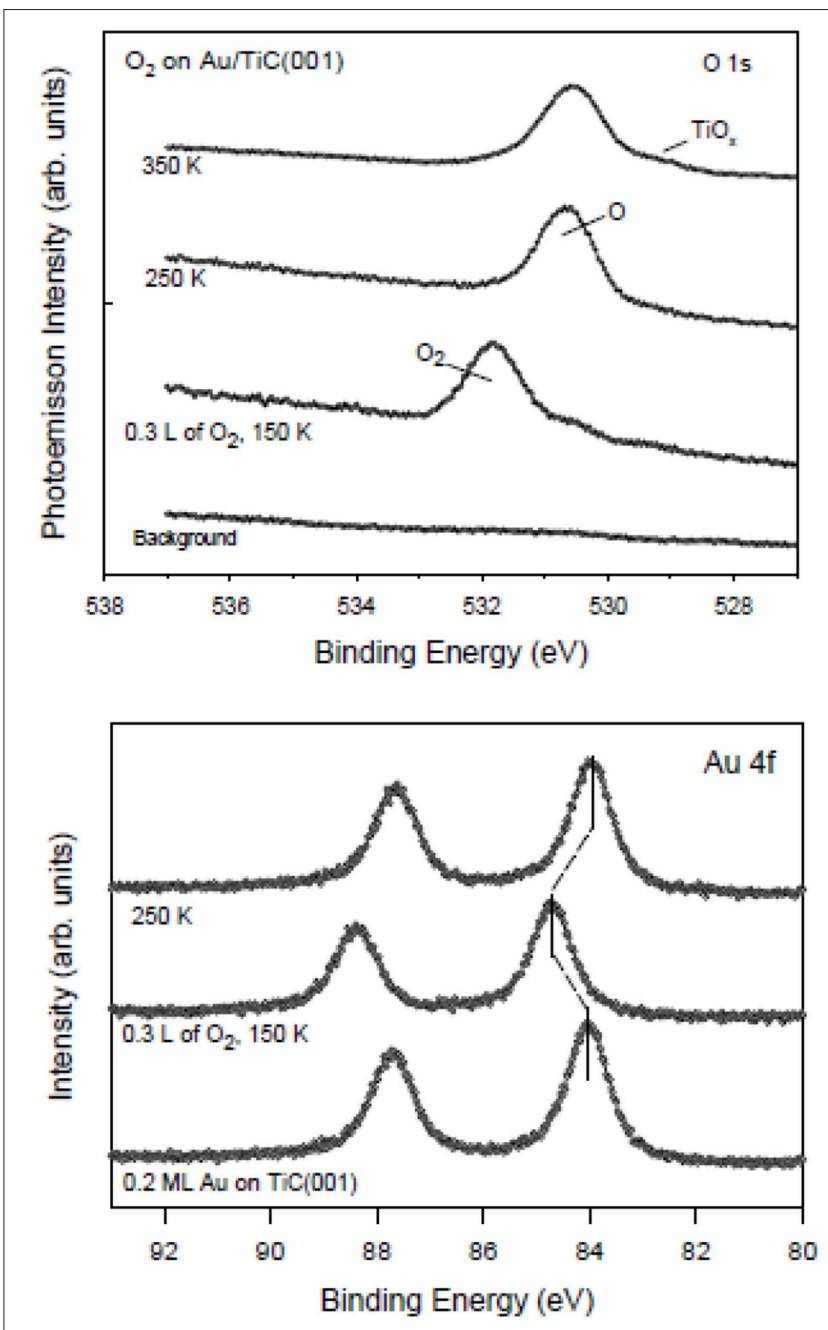

FIGURE 2 | Results of XPS, O 1s (top panel) and Au 4 f regions (bottom panel), collected after dosing $\mathrm{O}_{2}$ to a $\mathrm{TiC}(001)$ substrate with $0.2 \mathrm{ML}$ of gold. The initial dosing of molecular $\mathrm{O}_{2}$ was done at $150 \mathrm{~K}$. Then, the $\mathrm{O}_{2} / \mathrm{Au} / \mathrm{TiC}(001)$ surface was annealed to 250 and $350 \mathrm{~K}$. Reproduced with permission from Rodriguez et al. (2010), copyright 2010 by the American Society of Chemistry.

the $\mathrm{O}-\mathrm{O}$ bond is not broken, but the $\mathrm{O}_{2}$ molecule has been activated and can react with $\mathrm{CO}$ molecules initially bound to $\mathrm{TiC}(001)$ surface or directly attached to gold (Rodriguez et al., 2010). The photoemission results displayed in Figure 2 indicate that $\mathrm{Au} / \mathrm{TiC}(001)$ interacts well with $\mathrm{O}_{2}$. At $150 \mathrm{~K}$, $\mathrm{O}_{2}$ is chemisorbed but at higher temperatures it dissociates to produce $\mathrm{O}$ adatoms that can react with $\mathrm{CO}$ in an oxidation process (Rodriguez et al., 2010).

\section{WATER-GAS SHIFT REACTION}

Gold nanoparticles dispersed on $\mathrm{TiC}, \mathrm{MoC}$, and $\mathrm{Mo}_{2} \mathrm{C}$ display high activity for the low temperature water-gas shift (LT-WGS) reaction (Rodriguez et al., 2014; Posada-Perez et al., 2017; Yao et al., 2017). As mentioned above, and shown in Figure 1, small clusters of gold in direct contact with $\mathrm{TiC}(001)$ exhibit 
important electronic perturbations (Rodriguez et al., 2007). A similar phenomenon has been found after depositing the noble metal on surfaces of carbides of molybdenum and other metals. DF calculations were performed to examine in a systematic way the electronic structure of a series of small gold clusters $\left(\mathrm{Au}_{2}\right.$, $\mathrm{Au}_{4}, \mathrm{Au}_{9}, \mathrm{Au}_{13}$, and $\mathrm{Au}_{14}$ ) bounded to the (001) surface of various transition metal carbides $(\delta-\mathrm{MoC}, \mathrm{TiC}, \mathrm{VC}$, and $\mathrm{ZrC})$ (Florez et al., 2009). On these surfaces, the $\mathrm{C}$ sites exhibited strong interactions with the gold clusters. Bonding to the atoms of the underlying carbide strongly modified the electronic structure and charge density of the bound metal clusters. For 2D gold systems in direct contact with the carbide substrates, the electronic perturbations were quite strong (see Figure 3), but they gradually decreased when going to two-layer and three-layer gold systems. In general, the results of the DF calculations suggest that $\mathrm{Au}$ atoms in contact with carbide surfaces could be catalytically active (Florez et al., 2009). For $\mathrm{Au} / \mathrm{TiC}$ and $\mathrm{Au} / \mathrm{MoC}$, this prediction has been verified at an experimental level for the LTWGS reaction (Rodriguez et al., 2014; Posada-Perez et al., 2017; Yao et al., 2017).
The WGS activity for plain $\mathrm{TiC}(001)$ and $\mathrm{Au} / \mathrm{TiC}(001)$ systems with a broad set of gold coverages is shown in Figure 4 (Rodriguez et al., 2014). The clean $\mathrm{TiC}(001)$ is a catalyst for the water-gas shift. Interestingly, at a temperature of $450 \mathrm{~K}, \mathrm{TiC}(001)$ has a WGS activity larger than that of $\mathrm{Cu}(111)$ (Nakamura et al., 1990), which is a common benchmark in WGS studies (Nakamura et al., 1990; Gokhale et al., 2008). Extended surfaces of metallic $\mathrm{Au}$ are not able to catalyze the WGS process ( $\mathrm{Si}$ et al., 2012). In spite of this, the addition of gold to a $\mathrm{TiC}(001)$ surface largely enhances the WGS activity of the system. A maximum for the generation $\mathrm{CO}_{2}$ and $\mathrm{H}_{2}$ is detected at a $\mathrm{Au}$ coverage of $\sim 0.15 \mathrm{ML}$. Beyond this coverage, the WGS activity of $\mathrm{Au} / \mathrm{TiC}(001)$ gradually decreases (Rodriguez et al., 2014). Images of STM indicate that at coverages below $0.2 \mathrm{ML}$, Au grows on $\mathrm{TiC}(001)$ forming a large amount of $2 \mathrm{D}$ particles where the gold atoms are bonded to the $\mathrm{C}$ sites of the substrate and undergo an electron polarization which increases their chemical reactivity (Rodriguez et al., 2007, 2014; Rodriguez and Illas, 2012). At $\mathrm{Au}$ coverages above $0.2 \mathrm{ML}$, the admetal prefers the formation of $3 \mathrm{D}$ particles (i.e., a big fraction of the gold atoms are not

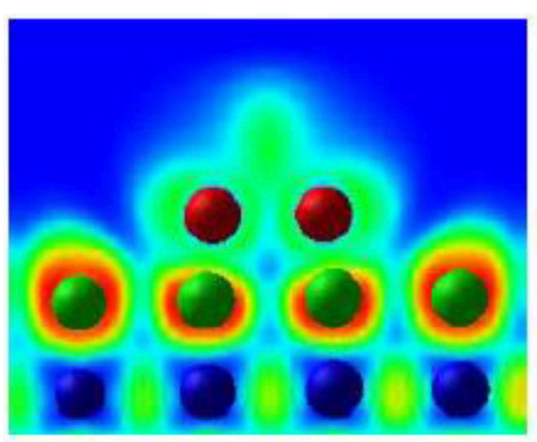

$\mathrm{Au}_{4} / \mathrm{TiC}$

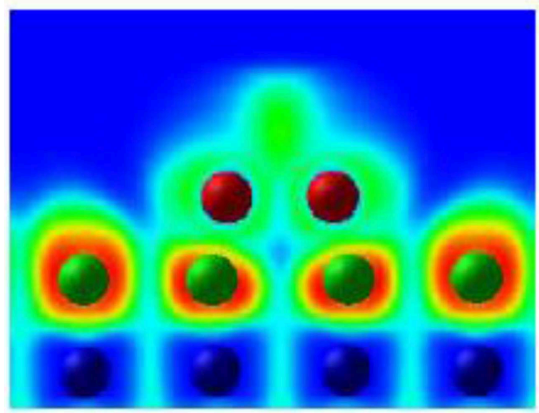

$\mathrm{Au}_{4} / \mathrm{ZrC}$

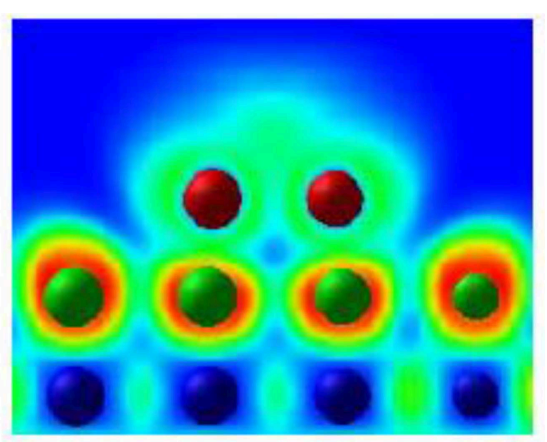

$\mathrm{Au}_{4} / \mathrm{VC}$

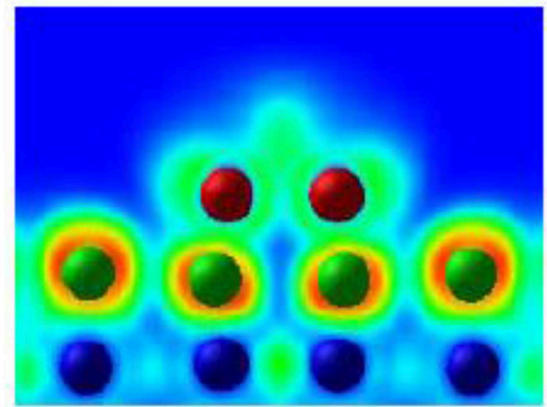

$\mathrm{Au}_{4} / \mathrm{\delta}-\mathrm{MoC}$

0

FIGURE 3 | Calculated electron densities for a Aus cluster on different carbide substrates. Reproduced with permission from Florez et al. (2009), copyright 2009 by the American Chemical Society. 
in contact with the carbide support and do not have special chemical properties).

In Figure 4, the WGS activity of $\mathrm{Au} / \mathrm{TiC}(001)$ and $\mathrm{Au} / \mathrm{TiO}_{2}(110)$ catalysts with similar amounts of the admetal is compared (Rodriguez et al., 2014). In the range of 550-625 K, $\mathrm{Au} / \mathrm{TiO}_{2}$ is an excellent catalyst for the WGS exhibiting a higher activity than that seen for $\mathrm{Cu} / \mathrm{ZnO}$ which is a common industrial WGS catalyst ( $\mathrm{Si}$ et al., 2012). However, at $450 \mathrm{~K}$, the data in Figure 4 indicate that $\mathrm{Au} / \mathrm{TiC}(001)$ is the superior lowtemperature WGS catalyst. This is corroborated by the results displayed in the Arrhenius graph of Figure 5 where the apparent activation energy for the WGS process drops from $18 \mathrm{kcal} / \mathrm{mol}$ on $\mathrm{Cu}(111)$ to $10 \mathrm{kcal} / \mathrm{mol}$ on $\mathrm{Au} / \mathrm{TiO}_{2}(110)$ and $8 \mathrm{kcal} / \mathrm{mol}$ on $\mathrm{Au} / \mathrm{TiC}(001)$. At temperatures below $500 \mathrm{~K}$, the $\mathrm{Au} / \mathrm{TiC}(001)$ system has a WGS activity which is observed on pure $\mathrm{Cu}$ surfaces and on $\mathrm{Cu}$ /oxide or $\mathrm{Au}$ /oxide (oxide $=\mathrm{TiO}_{2}, \mathrm{ZnO}, \mathrm{CeO}_{2}, \mathrm{MgO}$ ) catalysts only at elevated temperatures (>550 K) (Burch, 2006; Rodriguez et al., 2014). At low temperatures the active sites of the oxide-based systems are usually poisoned by carbonate and formate species. These species have a limited stability on carbide-based catalysts (Rodriguez et al., 2014; Posada-Perez et al., 2017; Yao et al., 2017).

DF calculations were used to determine the corresponding reaction profiles for the WGS on clean $\mathrm{TiC}(001)$ and a $\mathrm{Au} / \mathrm{TiC}(001)$ catalyst, see Figure 6 (Rodriguez et al., 2014). Figure 7 shows the calculated geometries for the reaction intermediates and the corresponding transition states. A $\mathrm{Au}_{4} / \mathrm{TiC}(001)$ model was used to represent the catalyst. Such a model contains the electronic perturbations produced by bonding gold to the carbide (Figure 1) and reflects the high activity seen for very small coverages of gold on titanium carbide (Rodriguez et al., 2014). In Figure 7, the essential steps for the WGS reaction occur on the gold sites. The DF calculations

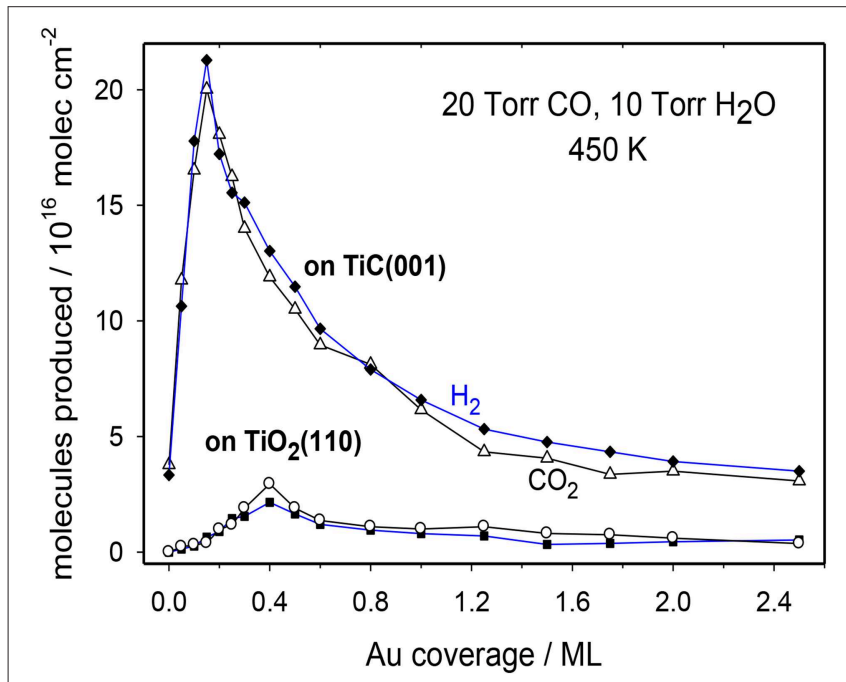

FIGURE 4 | Catalytic activity for the LT-WGS on Au/TiC(001) and $\mathrm{Au} / \mathrm{TiO}_{2}(110)$ surfaces as a function of Au coverage. $\mathrm{T}=450 \mathrm{~K}, 10$ Torr of $\mathrm{H}_{2} \mathrm{O}$ and 20 Torr of CO. Reproduced with permission from Rodriguez et al. (2014), copyright 2014 by Wiley. indicate that on $\mathrm{Au} / \mathrm{TiC}(001)$ the most favorable path for the WGS involves an associative mechanism where a HOCO species is generated by the interaction of $\mathrm{CO}$ with an $\mathrm{OH}$ group produced by the dissociation of adsorbed $\mathrm{H}_{2} \mathrm{O}$. The existence of a key $\mathrm{HOCO}$ intermediate, which decomposes into $\mathrm{CO}_{2}$ and $\mathrm{H}$, also has been proposed on many metal and metal/oxide catalysts
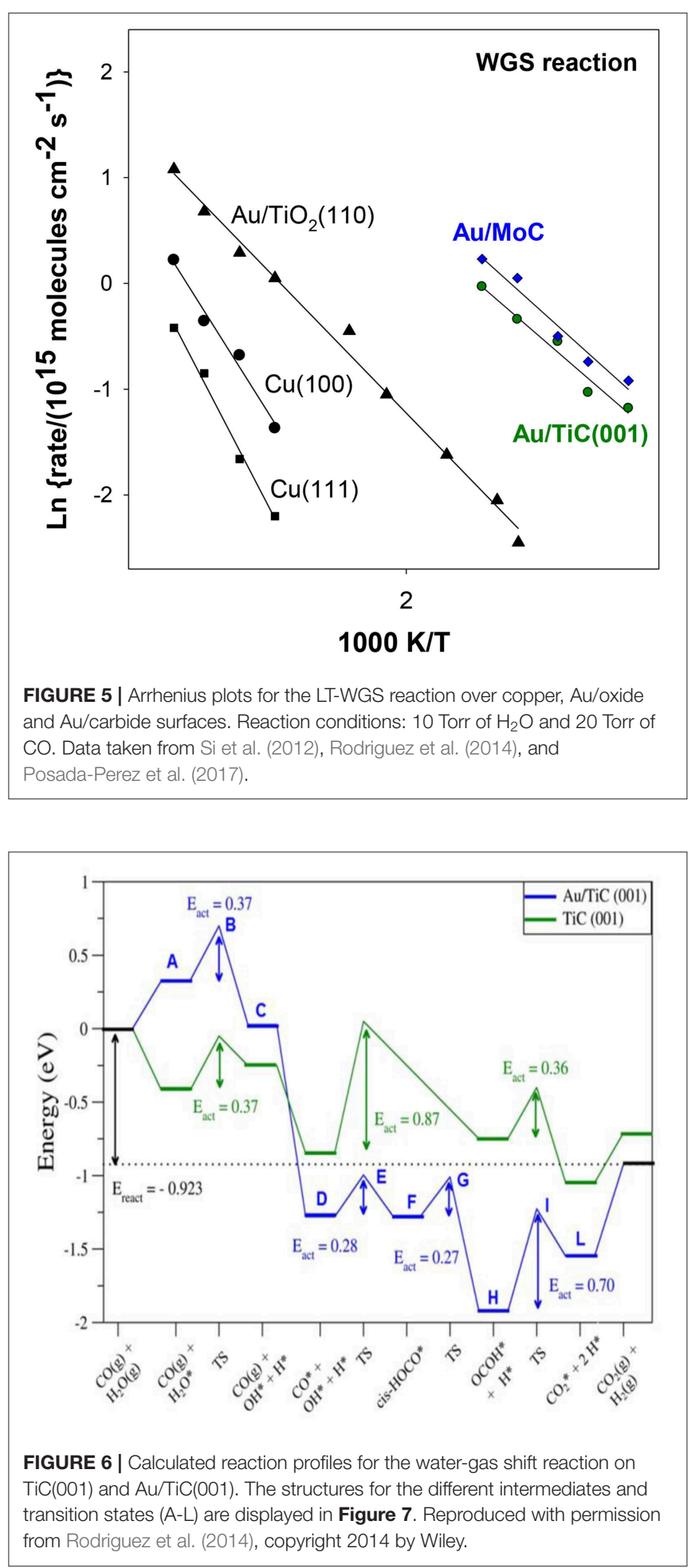

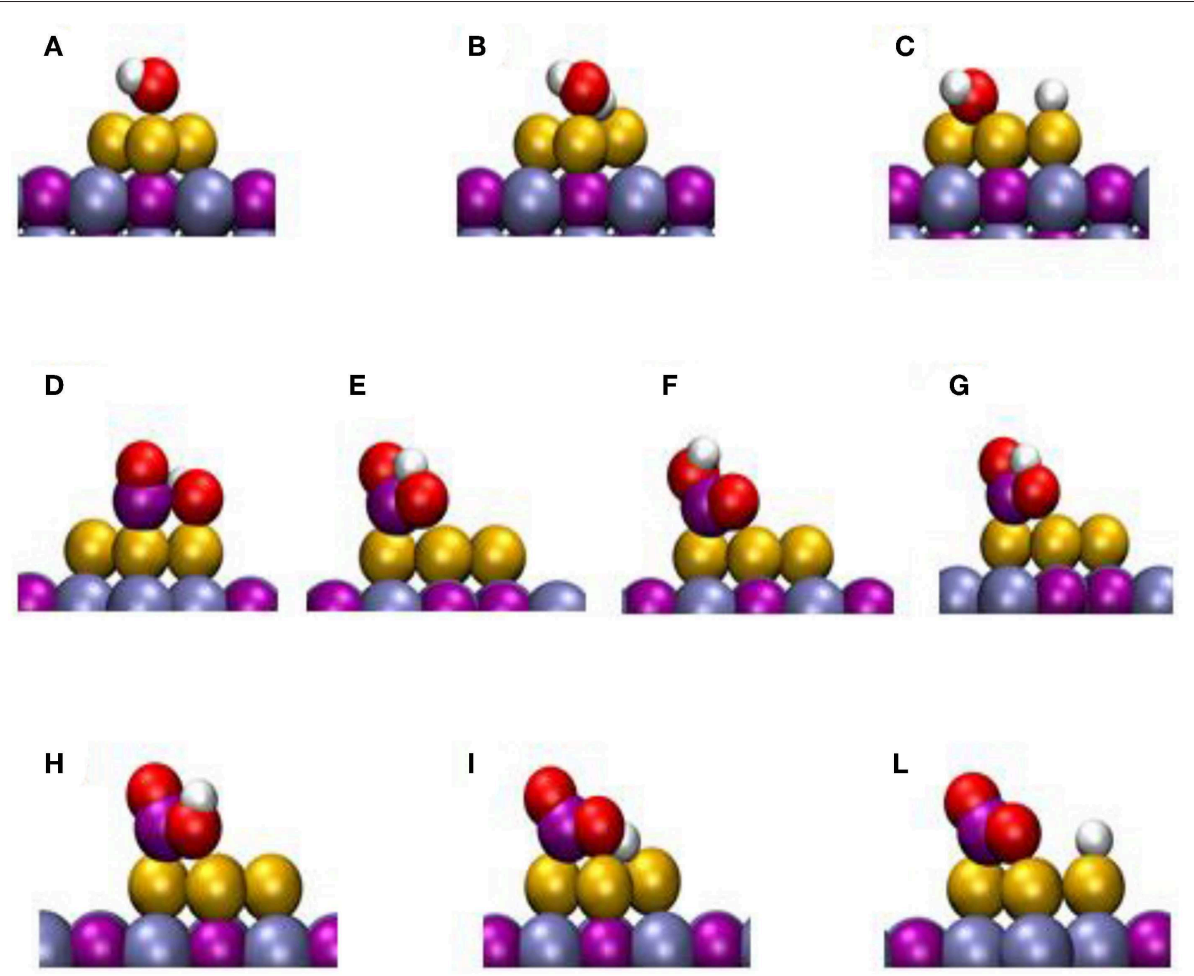

FIGURE 7 | Calculated structures for different intermediates of the WTS reaction on Au/TiC(001). The labels refer to specify states in Figure 6. Reproduced with permission from Rodriguez et al. (2014), copyright 2014 by Wiley.

(Burch, 2006; Gokhale et al., 2008). Over TiC(001), the rate constant calculated for the $\mathrm{OH}+\mathrm{CO} \rightarrow$ cis-HOCO reaction was only $3.20 \mathrm{~s}^{-1}$ site $^{-1}$, while the corresponding rate was $4.14 \times$ $10^{8} \mathrm{~s}^{-1}$ site $^{-1}$ over $\mathrm{Au}_{4} / \mathrm{TiC}(001)$ (Rodriguez et al., 2014). The surfaces of metallic gold do not cleave the $\mathrm{O}-\mathrm{H}$ bonds of water. In contrast, the calculated rate constant for the dissociation of $\mathrm{H}_{2} \mathrm{O}$ over a $\mathrm{Au}_{4}$ aggregate deposited on $\mathrm{TiC}(001)$ was $2.02 \times 10^{9} \mathrm{~s}^{-1}$ site $^{-1}$ (Rodriguez et al., 2014). The fast dissociation of water and the fast formation of the HOCO lead to a high catalytic activity for $\mathrm{Au} / \mathrm{TiC}$.

The deposition of gold on different surfaces of molybdenum carbide also produces excellent catalysts for the LT-WGS reaction (Posada-Perez et al., 2017; Yao et al., 2017). In Figure 5, the $\mathrm{Au} / \mathrm{MoC}$ system displays a somewhat better activity than $\mathrm{Au} / \mathrm{TiC}(001)$ when tested under similar reaction conditions (Rodriguez et al., 2014; Posada-Perez et al., 2017). In the case of $\mathrm{Au} / \mathrm{MoC}$, experimental studies do show a clear correlation between the ability of the system to dissociate water and its LT-WGS activity (Posada-Perez et al., 2017). In Figure 8, the amount of $\mathrm{OH}$ groups deposited on the surface upon interaction with water increased when small coverages of $\mathrm{Au}$ $(<0.25 \mathrm{ML})$ were deposited on MoC. These Au/MoC surfaces displayed a very high activity for the LT-WGS reaction. In $\mathrm{Au}$ 4f XPS spectra, there was a binding energy shift that is consistent with the direct dissociation of water on the supported gold. At large coverages of $\mathrm{Au}(>0.25 \mathrm{ML}), 3 \mathrm{D}$ particles were formed diminishing the interaction of $\mathrm{Au}$ atoms with the carbide substrate (Posada-Perez et al., 2017). As a result of this, the ability of the $\mathrm{Au} / \mathrm{MoC}$ to dissociate water and catalyze the LT-WGS process diminished (PosadaPerez et al., 2017). In the $\mathrm{Au} / \mathrm{MoC}$ and $\mathrm{Au} / \mathrm{TiC}(001)$ systems, the highest catalytic activity is found at very low coverages of gold.

Figure 9 compares the stability of $\mathrm{Au} / \mathrm{MC}$ and $\mathrm{Au} / \mathrm{Mo}_{2} \mathrm{C}(001)$ catalysts (Posada-Perez et al., 2017). No signs of deactivation are observed for the $\mathrm{Au} / \mathrm{MoC}$ system but there is a clear drop in the catalytic activity of $\mathrm{Au} / \mathrm{Mo}_{2} \mathrm{C}(001)$. The $\mathrm{Mo}_{2} \mathrm{C}$ is very aggressive toward the oxygen present in the water molecule. Eventually $\mathrm{Mo}_{2} \mathrm{C}$ is transformed into an oxycarbide and the $\mathrm{Au} \leftrightarrow$ carbide interactions disappear with a continuous drop in catalytic activity (Posada-Perez et al., 2017). Thus, an important parameter to consider when designing $\mathrm{Au} /$ carbide catalysts is the metal/carbon ratio in the carbide support (Rodriguez et al., 2010). This ratio is extremely important because it conditions the reactivity of the metal component in the carbide (Liu and Rodriguez, 2004; Hwu and Chen, 2005). In the case of $\mathrm{TiC}$ and $\mathrm{MoC}$, the high concentration of $\mathrm{C}$ diminishes the reactivity of the metal centers toward $\mathrm{O}$-containing molecules and at the same time $\mathrm{C}$ atoms help to activate the supported $\mathrm{Au}$ (Rodriguez and Illas, 2012).

A novel synthetic procedure was used to synthesize atomiclayered Au clusters on a $\alpha$-MoC substrate (Yao et al., 2017). Images for the $\mathrm{Au} / \alpha-\mathrm{MoC}$ catalyst obtained using aberrationcorrected scanning transmission electron microscopy (STEM) 

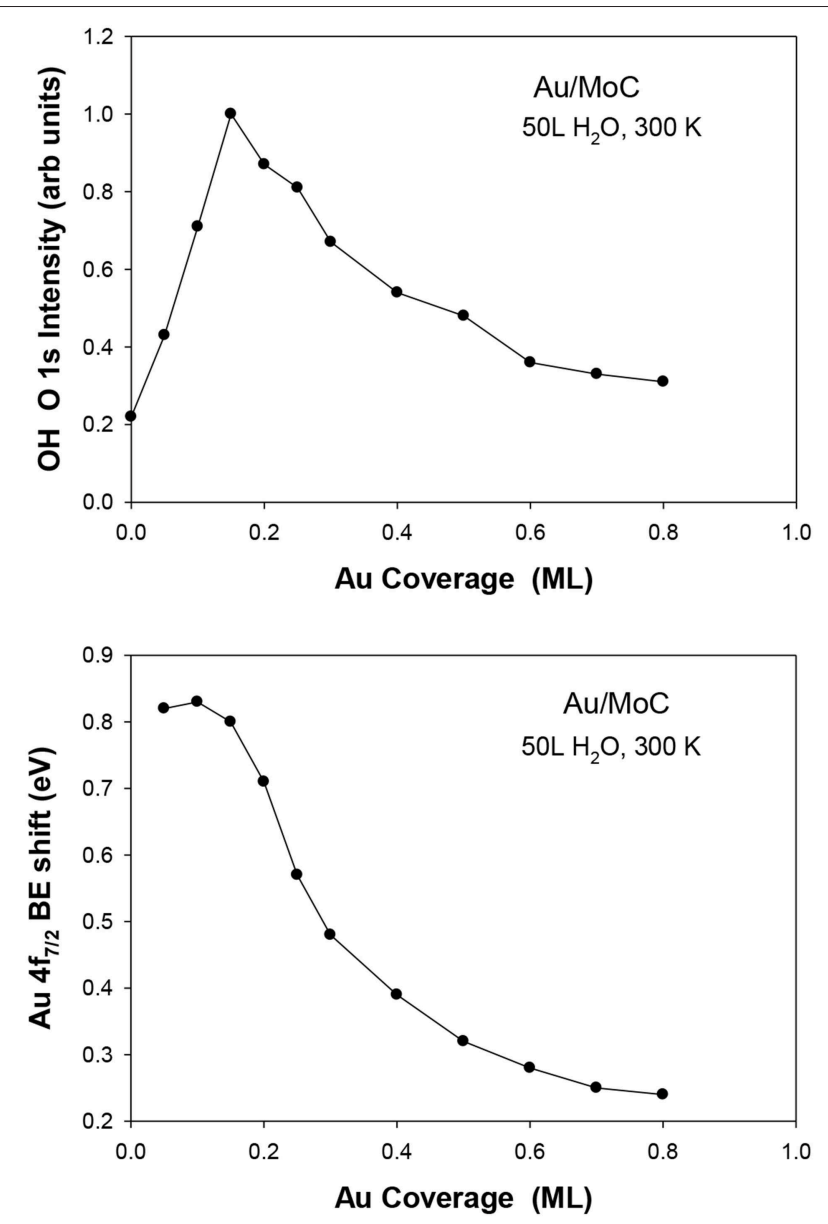

FIGURE 8 | Results of XPS collected after dosing 50 langmuir $(L)$ of water at $300 \mathrm{~K}$ to $\delta-\mathrm{MoC}$ and $\mathrm{Au} / \delta-\mathrm{MoC}$ surfaces. Top: Amount of $\mathrm{OH}$ seen in the $\mathrm{O} 1 \mathrm{~s}$ region. Bottom: Corresponding binding shift in the $A u 4 f_{7 / 2}$ binding energy. Reproduced with permission from Posada-Perez et al. (2017), copyright 2017 by Royal Society of Chemistry.

analysis showed that the catalyst structure contained porous assemblies of small $\alpha-\mathrm{MoC}$ nanoparticles with a size in the range of 3 to $20 \mathrm{~nm}$ and rich in defects. High-resolution STEM Zcontrast imaging showed two kinds of gold species on the surface of the catalyst: (i) small layered gold aggregates epitaxially grown on the $\alpha$-MoC substrate and (ii) atomically dispersed gold (Yao et al., 2017). The gold aggregates had an average diameter of 1 to $2 \mathrm{~nm}$ with a thickness of 2 to 4 atomic layers $(<1 \mathrm{~nm})$. Catalytic tests showed that both types of supported gold systems were catalytically active but the small layered Au clusters were the most active as catalysts for the LT-WGS process (Yao et al., 2017).

Results of ambient-pressure XPS showed dissociation of $\mathrm{H}_{2} \mathrm{O}$ over the $\alpha-\mathrm{MoC}$ component at room temperature, while the $\mathrm{CO}$ was bound to adjacent gold sites. This $\mathrm{CO}$ readily reacted with the surface $\mathrm{OH}$ groups formed from water, leading to a large LTWGS activity (390-476 K temperature range) (Yao et al., 2017). At $473 \mathrm{~K}$, the $\mathrm{Au} / \alpha-\mathrm{MoC}$ catalysts exhibited some deactivation but after testing over a period of $140 \mathrm{~h}$ the performance of the

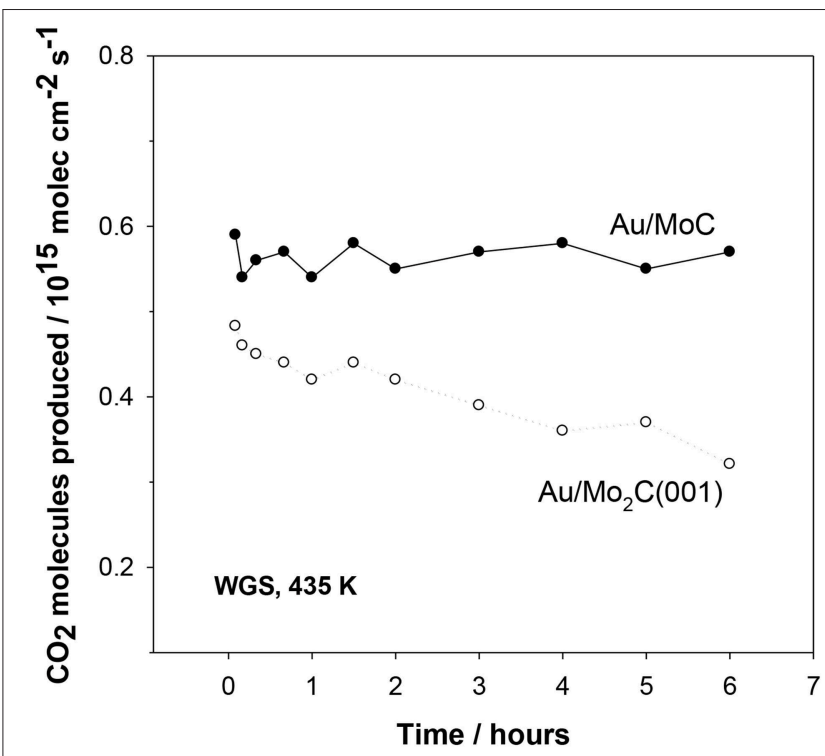

FIGURE 9 | Effect of time on the water-gas shift activity of $\mathrm{Au} / \delta-\mathrm{MoC}$ and $\mathrm{Au} / \beta-\mathrm{Mo}_{2} \mathrm{C}(001)$ surfaces. Initially, $0.15 \mathrm{ML}$ of $\mathrm{Au}$ were deposited on the carbide substrates and the obtained catalysts were exposed to 20 Torr of $\mathrm{CO}$ and 10 Torr of $\mathrm{H}_{2} \mathrm{O}$ at $435 \mathrm{~K}$. For the $\mathrm{Au} / \delta$-MoC system, the coverage of oxygen found after reaction with XPS remained constant $(\sim 0.25 \mathrm{ML})$. Such was not the case for the $\mathrm{Au} / \mathrm{Mo}_{2} \mathrm{C}(001)$ system, where a substantial coverage of oxygen was always present $(>0.5 \mathrm{ML}$ ) and rised with time causing the deactivation of the system. Reproduced with permission from Posada-Perez et al. (2017), copyright 2017 by Royal Society of Chemistry.

catalysts was stable with a CO conversion close to 50\% (Yao et al., 2017). A performance which was better than those of Au/oxide catalysts under the same conditions (Yao et al., 2017). The $\mathrm{Au} / \alpha-\mathrm{MoC}$ catalysts were not stable when exposed to the reactants of the WGS at high temperatures. Results of in-situ Xray diffraction, Figure 10, showed a progressive transformation of $\alpha-\mathrm{MoC}$ into $\mathrm{MoO}_{2}$ at temperatures above $500 \mathrm{~K}$ (Yao et al., 2017). The lack of stability got worse when $\alpha-\mathrm{MoC}$ was replaced with $\mathrm{B}-\mathrm{Mo}_{2} \mathrm{C}$ (Yao et al., 2017). Thus, two important parameters to consider when dealing with the long term performance of these systems are the temperature and metal/carbon ratio in the carbide component of the catalysts (Posada-Perez et al., 2017; Yao et al., 2017).

\section{$\mathrm{CO}_{2}$ HYDROGENATION TO METHANOL AND CO}

Carbon dioxide does not interact with gold at all, but when nanoparticles of the noble metal are deposited on surfaces of carbides, one obtains very good catalysts for the conversion of $\mathrm{CO}_{2}$ to methanol or CO (Vidal et al., 2012; Posada-Pérez et al., 2016). In general, the carbides by themselves are active catalysts for the conversion of $\mathrm{CO}_{2}$ (Dubois et al., 1992; Xu et al., 2014). Depending on the metal/carbon ratio in the carbide, the products of the of the $\mathrm{CO}_{2}$ hydrogenation reaction vary from $\mathrm{CO}$ to alcohols and to light alkanes (Dubois et al., 


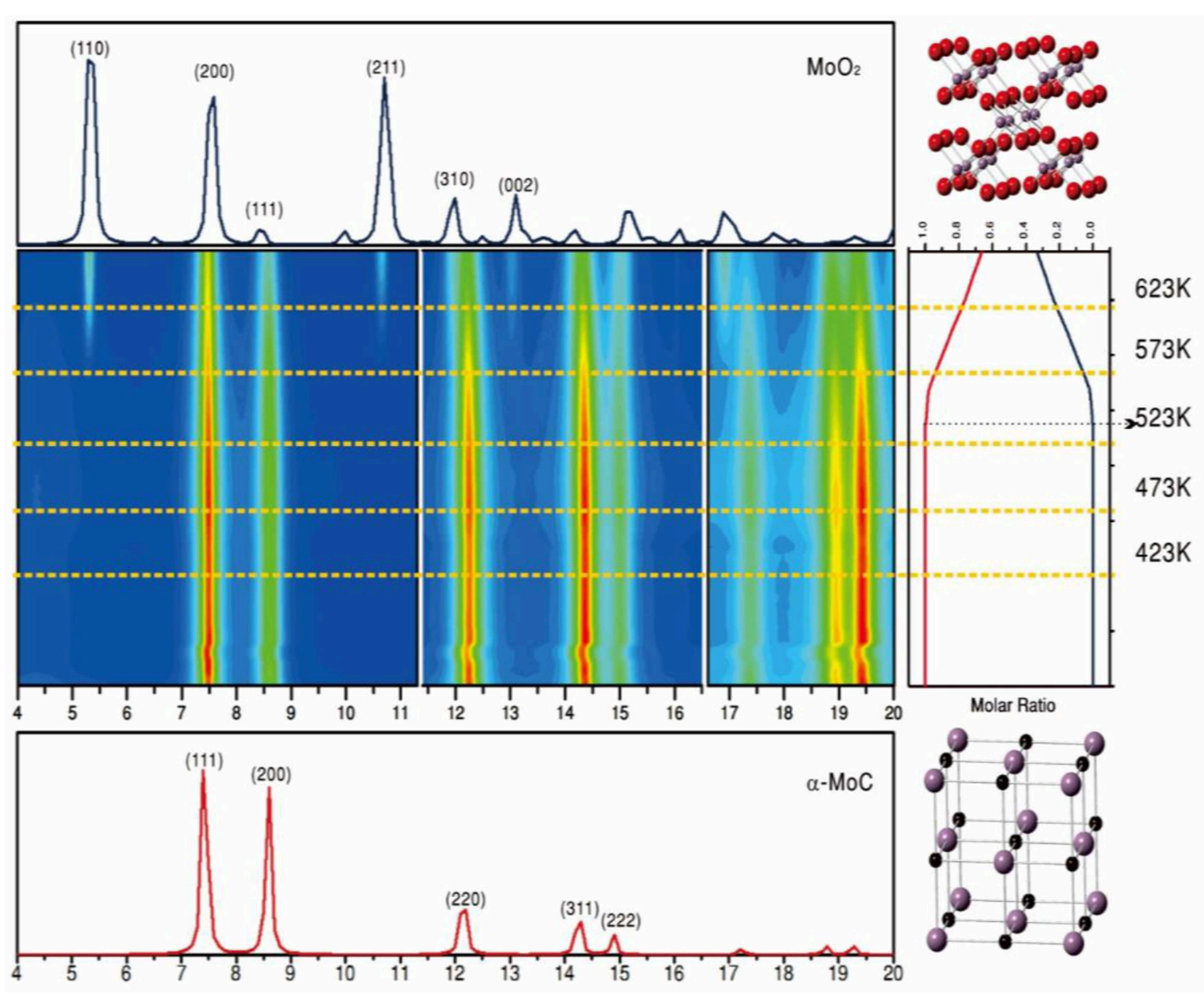

FIGURE 10 | In situ time-resolved X-ray diffraction patterns collected for a (2\%)Au/ $\alpha$-MoC powder catalyst at various temperatures under normal WGS reaction conditions (wavelength, $0.3196 \AA$ A). In the middle panel, the rainbow color scheme varies from no signal (blue) to very intense diffraction peaks (red). The crystal structures of $\alpha-\mathrm{MoC}$ and $\mathrm{MoO}_{2}$ are shown on the right side of the figure as ball-and-stick drawings (red, O; purple, Mo; black, C). Reproduced with permission from Yao et al. (2017), copyright 2017 by AAA Science.

1992; Xu et al., 2014). When the metal/carbon ratio is close to one, $\mathrm{CO}$ and methanol are the main products for the hydrogenation of $\mathrm{CO}_{2}$ over a carbide catalyst (Dubois et al., 1992; Xu et al., 2014; Posada-Pérez et al., 2016). Theoretical calculations have shown that, in general, $\mathrm{CO}_{2}$ binds well on $\mathrm{MC}(001)$ surfaces $(\mathrm{M}=\mathrm{Ti}, \mathrm{Mo}, \mathrm{Zr}, \mathrm{Hf}, \mathrm{Nb}, \mathrm{Ta}, \mathrm{Hf}$, and $\mathrm{W})$ (Vidal et al., 2012; Posada-Perez et al., 2014; Posada-Pérez et al., 2016; Kunkel et al., 2016; Dixit et al., 2017; Koverga et al., 2019).

Figure 11 shows results of DF calculations for the bonding geometry of the $\mathrm{CO}_{2}$ molecule on plain $\mathrm{TiC}(001)$ (Vidal et al., 2012). The molecule binds in a seudo- $\eta^{3}-\mathrm{C}, \mathrm{O}, \mathrm{O}$ configuration with one single $\mathrm{C}$ - $\mathrm{C}$ bond (1.48 $\AA$ in length) and two weak Ti-O bonds ( $2.24 \AA$ in length). A net carbide $\rightarrow \mathrm{CO}_{2}$ electron transfer leads to activation and bending of the $\mathrm{CO}_{2}$ molecule on $\mathrm{TiC}(001)$. The $\mathrm{CO}_{2}$ adsorption process induces an elongation of the C-O bonds from $1.17 \AA$ in the free molecule (gas phase) to $1.29 \AA$ on the carbide surface. An adsorption energy of $-0.62 \mathrm{eV}$ was calculated for the $\mathrm{CO}_{2}$ on $\mathrm{TiC}(001)$. This is a moderate value for a binding energy but in magnitude it is still much larger than adsorption energies found in experimental and theoretical studies for $\mathrm{CO}_{2}$ interacting with surfaces of copper and late transition metals (Freund and Messmer, 1986; Freund and Roberts, 1996; Taifan et al., 2016). Substantial binding energies have also been calculated for $\mathrm{CO}_{2}$ on other $\mathrm{MC}(001)$ surfaces with the molecule mainly interacting with C sites of the carbide (Vidal et al., 2012; Posada-Perez et al., 2014; Posada-Pérez et al., 2016; Kunkel et al., 2016). On carbide surfaces, an extremely strong interaction has been observed for $\mathrm{CO}_{2}$ on $\beta-\mathrm{Mo}_{2} \mathrm{C}(001)$ (Ren et al., 2006; Posada-Perez et al., 2014), where the low $\mathrm{C} /$ metal ratio leads to $\mathrm{CO} 2 \rightarrow \mathrm{CO} \rightarrow \mathrm{C}$ transformations below room temperature and DF calculations show an almost spontaneous cleavage of the first $\mathrm{C}-\mathrm{O}$ bond (Posada-Perez et al., 2014).

The trends observed in theoretical studies (Yang et al., 2013; Posada-Pérez et al., 2016) indicate that a 1:1 carbon-to-metal ratio is the best option if one is interested in the conversion of $\mathrm{CO}_{2}$ to oxygenates and wants to reduce methane formation. The addition of small gold particles to $\mathrm{TiC}(001)$ and $\mathrm{MoC}(001)$ surfaces produces systems with remarkable activity for the 




FIGURE 11 | Adsorption geometries obtained with DF calculations for $\mathrm{CO}_{2}$ on $\mathrm{TiC}(001)$ and $\mathrm{Au}_{4} / \mathrm{TiC}(001)$ surfaces. Reproduced with permission from Vidal et al. (2012), copyright 2012 by the American Chemical Society of Chemistry.

hydrogenation of $\mathrm{CO}_{2}$ to methanol (Vidal et al., 2012; PosadaPérez et al., 2016). At the bottom of Figure 11, one can see the calculated geometry for the binding of $\mathrm{CO}_{2}$ to a $\mathrm{Au}_{4} / \mathrm{TiC}(001)$ system (Vidal et al., 2012). The $\mathrm{CO}_{2}$ binding energy over $\mathrm{Au}_{4} / \mathrm{TiC}(001)$ was substantial, $-0.68 \mathrm{eV}$, and the molecule was attached to the gold atoms with a $\eta^{2}-\mathrm{C}, \mathrm{O}$ conformation. In contrast, the binding energy of $\mathrm{CO}_{2}$ on extended surfaces of metallic gold or unsupported (i.e., free) gold nanoparticles is zero (Freund and Messmer, 1986; Freund and Roberts, 1996; Vidal et al., 2012). On $\mathrm{Au}_{4} / \mathrm{TiC}(001)$, the molecule exhibits the bended geometry of a charged species (Vidal et al., 2012) with a significant elongation $(0.05-0.11 \AA)$ of the $\mathrm{C}-\mathrm{O}$ bonds with respect to the calculated value in gas phase (1.17 $\AA$, see above) (Vidal et al., 2012). Thus, one can conclude that a $\mathrm{Au}_{4} / \mathrm{TiC}(001)$ surface clearly activates the $\mathrm{CO}_{2}$ molecule.

The hydrogenation of $\mathrm{CO}_{2}$ on $\mathrm{Au} / \mathrm{TiC}(001)$ and $\mathrm{Au} / \mathrm{MoC}$ yields $\mathrm{CO}$, the main reaction product, and methanol (Vidal et al., 2012; Posada-Pérez et al., 2016). The amount of CO produced is 2-3 orders of magnitude bigger than the yield of methanol. The amount of gold deposited on the carbide surface has a very strong effect on the activity of the system, Figure 12. An optimum performance was found at Au coverages of $0.1-$ $0.2 \mathrm{ML}$, when there was a large amount of small $2 \mathrm{D}$ clusters on the carbide substrates (Vidal et al., 2012; Posada-Pérez et al., 2016). Large 3D clusters of Au display a low activity for $\mathrm{CO}_{2}$ hydrogenation pointing to the need of electronic perturbations in the $\mathrm{Au}$ adatoms. In Figure 11, a flat $\mathrm{Au}_{4}$ cluster binds the $\mathrm{CO}_{2}$ molecule well, but when the $\mathrm{Au}_{4}$ is replaced by a 13-atom pyramid of gold (see Figure 1), there is no binding of the $\mathrm{CO}_{2}$ molecule (Vidal et al., 2012; Posada-Pérez et al., 2016).

Figure 13 displays Arrhenius plots for the generation of $\mathrm{CH}_{3} \mathrm{OH}$ on $\mathrm{Au} / \mathrm{TiC}(001)$ and $\mathrm{Au} / \mathrm{MoC}$ (Vidal et al., 2012; Posada-Pérez et al., 2016). For comparison are included

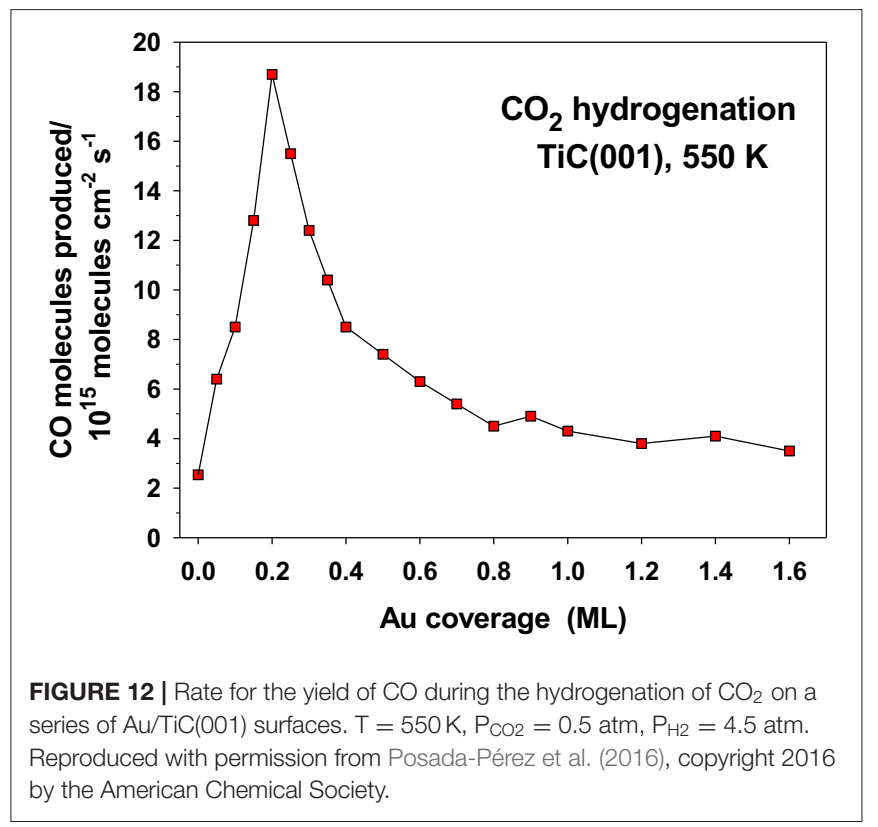

results for $\mathrm{Cu}(111)$ and a system which models an industrial $\mathrm{Cu} / \mathrm{ZnO}$ catalyst for methanol synthesis. The calculated apparent activation energies for methanol and CO production are listed in Table 1. In the case of methanol synthesis, the apparent activation energy drops from a value of $25 \mathrm{Kcal} / \mathrm{mol}$ on $\mathrm{Cu}(111)$ to 13 and $12 \mathrm{kcal} / \mathrm{mol}$ for $\mathrm{Au}$ supported over $\mathrm{TiC}(001)$ and $\mathrm{MoC}$ (Vidal et al., 2012; Posada-Pérez et al., 2016). These surfaces exhibited a methanol production rate that was 8-11 times larger than that seen for $\mathrm{Cu} / \mathrm{ZnO}(000 \mathrm{i})$, Figure 13, illustrating the great advantage of using a carbide as a metal support (Vidal et al., 


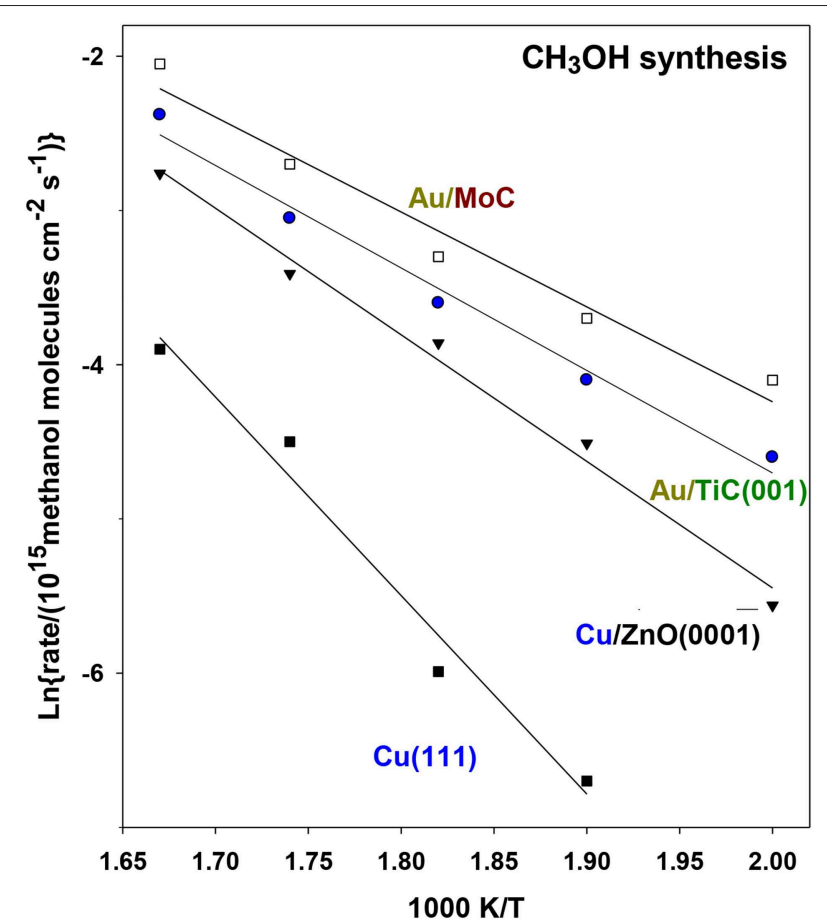

FIGURE 13 | Arrhenius plots for the generation of $\mathrm{CH}_{3} \mathrm{OH}$ through $\mathrm{CO}_{2}$ hydrogenation on a several Au-containing catalysts. Initially, $0.2 \mathrm{ML}$ of gold were deposited on $\mathrm{MoC}$ and $\mathrm{TiC}(001)$. In a batch reactor, both catalysts were exposed to $0.049 \mathrm{MPa}(0.5 \mathrm{~atm})$ of $\mathrm{CO}_{2}$ and $0.441 \mathrm{MPa}(4.5 \mathrm{~atm})$ of $\mathrm{H}_{2}$ at temperatures of $600,575,550,525$, and $500 \mathrm{~K}$. Reproduced with permission from Posada-Pérez et al. (2016), copyright 2016 by the American Chemical Society.

TABLE 1 | Apparent activation energies for $\mathrm{CO}_{2}$ hydrogenation on a series of (in $\mathrm{kcal} / \mathrm{mol})^{\mathrm{a}}$.

\begin{tabular}{lcc}
\hline Catalyst & CO, RWGS & $\mathbf{C H}_{\mathbf{3}} \mathbf{O H}$ synthesis \\
\hline $\mathrm{Au} / \mathrm{\delta}-\mathrm{MoC}$ & 10 & 12 \\
$\mathrm{Au} / \mathrm{TiC}(001)$ & 14 & 13 \\
$\delta-\mathrm{MoC}$ & 18 & 17 \\
$\mathrm{TiC}(001)$ & 19 & 21 \\
$\mathrm{Cu} / \mathrm{ZnO}(000 \mathrm{i})$ & 14 & 16 \\
$\mathrm{Cu}(111)$ & 22 & 25
\end{tabular}

${ }^{a}$ From Posada-Pérez et al. (2016).

2012; Posada-Pérez et al., 2016). In Table 1 are listed apparent activation energies for $\mathrm{CH}_{3} \mathrm{OH}$ and $\mathrm{CO}$ formation on different catalysts. For a given surface, one can see similar values for $\mathrm{CH}_{3} \mathrm{OH}$ and $\mathrm{CO}$ formation hinting that $\mathrm{CO}$ production is the rate limiting step on all the metal/carbide surfaces. Thus, $\mathrm{CO}$ is probably formed first, through the reverse WGS reaction, and a fraction of the formed $\mathrm{CO}$ is further converted into methanol via selective hydrogenation steps (Vidal et al., 2012; Posada-Pérez et al., 2016).

After reaction, the existence of a minor coverage of oxygen $(\sim 0.1 \mathrm{ML})$ was detected with XPS over the TiC(001) and MoC
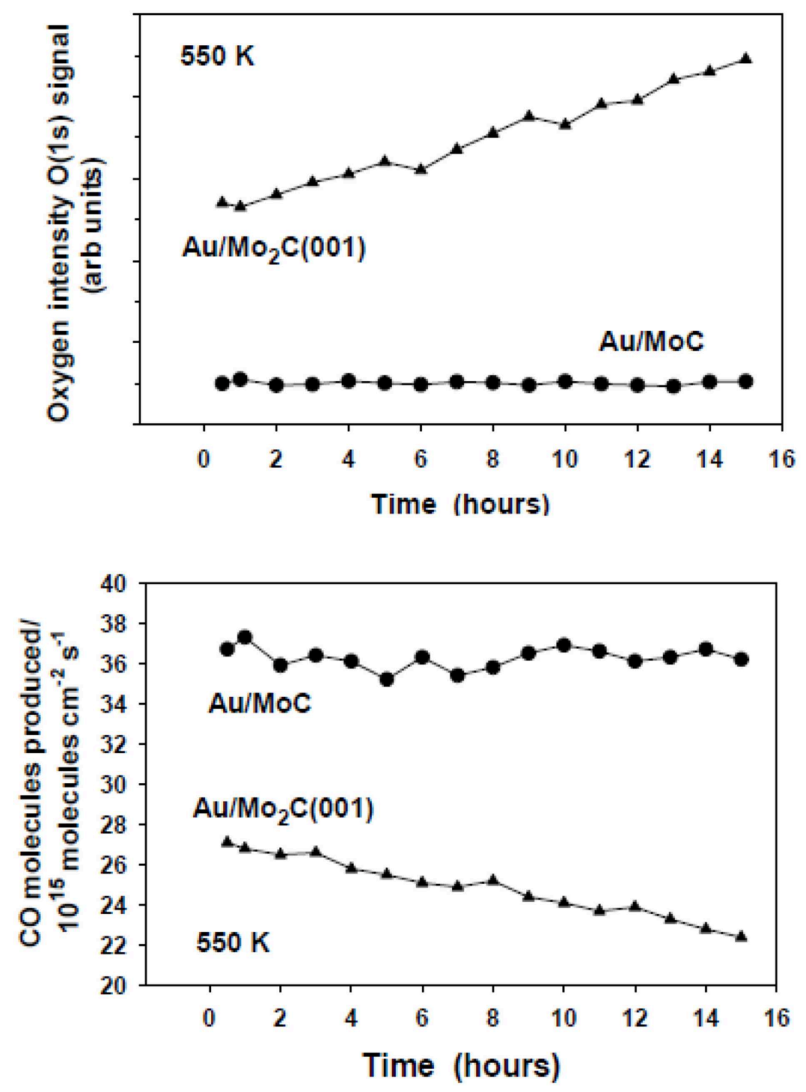

FIGURE 14 | Top: Coverages of O measured with XPS for $\mathrm{Au} / \beta-\mathrm{Mo}_{2} \mathrm{C}(001)$ and $\mathrm{Au} / \delta$-MoC catalysts $\left(\theta_{\mathrm{Au}} \sim 0.2 \mathrm{ML}\right.$ ) as a function of time under constant $\mathrm{CO}_{2}$ hydrogenation conditions. Bottom: Corresponding rate of $\mathrm{CO}$ generation over the $\mathrm{Au} / \beta-\mathrm{Mo}_{2} \mathrm{C}(001)$ and $\mathrm{Au} / \delta-\mathrm{MoC}$ catalysts as a function of time maintaining the same reaction mixture. In a batch reactor, both catalysts were exposed to $0.049 \mathrm{MPa}(0.5 \mathrm{~atm})$ of $\mathrm{CO}_{2}$ and $0.441 \mathrm{MPa}(4.5 \mathrm{~atm})$ of $\mathrm{H}_{2}$ at a temperature of $550 \mathrm{~K}$. Reproduced with permission from Posada-Pérez et al. (2016), copyright 2016 by the American Chemical Society.

substrates (Vidal et al., 2012; Posada-Pérez et al., 2016). The amount of oxygen present on these carbide catalysts did not increase with time producing a decrease in catalytic activity (see Figure 14). A completely opposite behavior was seen for $\mathrm{Au} / \beta-\mathrm{Mo}_{2} \mathrm{C}(001)$ where the amount of oxygen present on the surface was substantial $(>0.4 \mathrm{ML})$ and raised with time (Figure 14) probably as a consequence of the formation of an oxycarbide. Therefore, the $\mathrm{Au} / \beta-\mathrm{Mo}_{2} \mathrm{C}(001)$ catalyst displayed poor stability because the surface activity was reduced by $\mathrm{O}$ poisoning (Figure 14). These data point to the importance of the metal/carbon ratio in a transition metal carbide. It is a critical parameter to consider when aiming for a catalyst with good activity, selectivity, and stability for the hydrogenation of $\mathrm{CO}_{2}$ (Vidal et al., 2012; Posada-Pérez et al., 2016).

\section{CONCLUSION AND FUTURE WORK}

The experimental and theoretical results discussed above show that the electronic perturbations induced by the bonding of $\mathrm{Au}$ 
to a metal carbide have a strong impact on the performance of the noble metal in reactions associated with $\mathrm{C} 1$ catalysis such as the oxidation of $\mathrm{CO}$, the production of hydrogen via the watergas shift and the hydrogenation of $\mathrm{CO}_{2}$. On the carbide surfaces, the $\mathrm{Au}$ interacts stronger than on oxides opening the door for strong metal-support interactions.

So far, the experimental studies have been focused on a few reactions for $\mathrm{Au}$ particles supported on $\mathrm{MoC}$ and TiC. After studying the interaction of gold and several metal carbides with DF-based methods (Rodriguez and Illas, 2012), it is clear that the electronic perturbations on gold significantly rise when going from $\mathrm{TiC}$ to $\mathrm{ZrC}$ or $\mathrm{TaC}$ as a support. Thus, $\mathrm{Au} / \mathrm{ZrC}$ and $\mathrm{Au} / \mathrm{TaC}$ have the electronic properties necessary for being good catalysts and should be tested for $\mathrm{C} 1$ catalysis. Furthermore, the activity of the Au-carbide interfaces should be also tested for many of the reactions where catalytic activity has been observed on Au-oxide interfaces. For example, in the area of $\mathrm{C} 1$ chemistry, systematic studies must be carried out for CO-PROX (preferential CO oxidation), the hydrogenation of $\mathrm{CO}_{2}$ to $\mathrm{CH}_{4}$ or formic acid, or the reforming and manipulation of methanol.

\section{REFERENCES}

Burch, R. B. (2006). Gold catalysts for pure hydrogen production in the water-gas shift reaction: activity, structure and reaction mechanism. Phys. Chem. Chem. Phys. 8, 5483-5500. doi: 10.1039/B607837K

Campbell, C. (2004). The active site in nanoparticle gold catalysis. Science 306, 234-235. doi: 10.1126/science.1104246

Dixit, M., Peng, X., Porosoff, M. D., Willauer, H. D., and Mpourmpakis, G. (2017). Elucidating the role of oxygen coverage in $\mathrm{CO}_{2}$ reduction on $\mathrm{Mo}_{2}$ C. Catal. Sci. Technol. 7, 5521-5529. doi: 10.1039/C7CY01810J

Dubois, J.-L., Sayama, K., and Arakawa, H. (1992). $\mathrm{CO}_{2}$ hydrogenation over carbide catalysts. Chem. Lett. 5-8. doi: 10.1246/cl.1992.5

Florez, E., Feria, L., Viñes, F., Rodriguez, J. A., and Illas, F. (2009). Effect of the support on the electronic structure of Au nanoparticles supported on transition metal carbides: choice of the best substrate for Au activation. J. Phys. Chem. C 113, 19994-20001. doi: 10.1021/jp907043g

Freund, H.-J., and Messmer, R. P. (1986). On the bonding and reactivity of $\mathrm{CO}_{2}$ on metal surfaces. Surf. Sci. 172, 1-30. doi: 10.1016/0039-6028(86)90580-7

Freund, H.-J., and Roberts, M. W. (1996). Surface chemistry of carbon dioxide. Surf. Sci. Rep. 25, 225-273. doi: 10.1016/S0167-5729(96)00007-6

Fu, Q., Saltsburg, H., and Flytzani-Stephanopoulos, M. (2003). Active nonmetallic $\mathrm{Au}$ and Pt species on ceria-based water-gas shift catalysts. Science 301, 935-938. doi: $10.1126 /$ science. 1085721

Gokhale, A. A., Dumesic, J. A., and Mavrikakis, M. (2008). On the mechanism of the low-temperature water-gas shift reaction. J. Am. Chem. Soc. 130, 1402-1414. doi: $10.1021 / \mathrm{ja} 0768237$

Gu, X.-K., Qiao, B., Huang, C. Q., Ding, W. C., Sun, K., Zhan, E., et al. (2014). Supported single $\mathrm{Pt}_{1} / \mathrm{Au}_{1}$ atoms for methanol steam reforming. ACS Catal. 4 , 3886-3890. doi: 10.1021/cs500740u

Hammer, B., and Nørskov, J. K. (1995). Why gold is the noblest of all the metals. Nature 376, 238-240. doi: 10.1038/376238a0

Haruta, M. (1997). Size- and support-dependency in the catalysis of gold. Catal. Today 36, 153-166. doi: 10.1016/S0920-5861(96)00208-8

Hwu, H. H., and Chen, J. G. (2005). Surface chemistry of transition metal carbides. Chem. Rev. 105, 185-212. doi: 10.1021/cr0204606

Koverga, A. A., Florez, E., Dorkis, L., and Rodriguez, J. A. (2019). CO, $\mathrm{CO}_{2}$ and $\mathrm{H}_{2}$ interactions with (0001) and (001) tungsten carbide surfaces: importance of carbon and metal sites. J. Phys. Chem. C 123, 8871-8883. doi: 10.1021 /acs.jpcc.8b11840

Kunkel, C., Viñes, F., and Illas, F. (2016). Transition Metal carbides as novel materials for $\mathrm{CO}_{2}$ capture, storage and

\section{AUTHOR CONTRIBUTIONS}

The author confirms being the sole contributor of this work and has approved it for publication.

\section{FUNDING}

JR was funded by the US Department of Energy.

\section{ACKNOWLEDGMENTS}

The author is grateful to several coworkers at BNL (Ping Liu, Dario Stacchiola, Sanjaya Senanayake, J. Chen), the Universidad Central de Venezuela (J. Evans, P.J. Ramirez), the University of Barcelona (F. Illas, F. Viñes), the Tokyo Institute of Technology (K. Nakamura), and Peking University (D. Ma, S. Yao) for thought-provoking discussions about the properties of goldcarbide interfaces. The research carried out at BNL was supported by the US Department of Energy, Chemical Sciences Division under Contract No. DE-SC0012704. activation. Energy Environ. Sci. 9, 141-144. doi: 10.1039/C5EE0 $3649 \mathrm{~F}$

Liu, P., and Rodriguez, J. A. (2004). Effects of carbon on the stability and chemical performance of transition metal carbides: a density functional study. J. Chem. Phys. 120, 5414-5423. doi: 10.1063/1.1647050

Naitabdi, A., Ono, L. K., and Roldan Cuenya, B. (2006). Local investigation of the electronic properties of size-selected Au nanoparticles by scanning tunneling spectroscopy. Appl. Phys. Lett. 89:043101. doi: 10.1063/1.2233601

Nakamura, J., Campbell, J. M., and Campbell, C. T. (1990). Kinetics and mechanism of the water-gas shift reaction catalysed by the clean and Cs-promoted $\mathrm{Cu}(110)$ surface: a comparison with $\mathrm{Cu}(111)$. J. Chem. Soc. Faraday Trans. 86, 2725-2734. doi: 10.1039/ft99086 02725

Ono, L. K., and Roldan-Cuenya, B. (2007). Effect of interparticle interaction on the low temperature oxidation of $\mathrm{CO}$ over size-selected Au nanocatalysts supported on ultrathin TiC films. Catal. Lett. 113, 86-94. doi: 10.1007/s10562-007-9027-7

Ono, L. K., Sudfeld, D., and Roldan Cuenya, B. (2006). In situ gasphase catalytic properties of TiC-supported size-selected gold nanoparticles synthesized by diblock copolymer encapsulation. Surf. Sci. 600, 5041-5050. doi: 10.1016/j.susc.2006.08.025

Posada-Perez, S., Gutierrez, R. A., Zuo, Z., Ramirez, P. J., Viñes, F., Liu, P., et al. (2017). Highly active $\mathrm{Au} / \delta-\mathrm{MoC}$ and $\mathrm{Au} / \beta-\mathrm{Mo}_{2} \mathrm{C}$ catalysts for the low-temperature water gas shift reaction: effects of the carbide metal/carbon ratio on the catalyst performance. Catal. Sci. Technol. 7, 5332-5342. doi: 10.1039/C7CY00639J

Posada-Pérez, S., Ramírez, P. J., Evans, J., Viñes, F., Liu, P., Illas, F., et al. (2016). Highly active $\mathrm{Au} / \delta-\mathrm{MoC}$ and $\mathrm{Cu} / \delta-\mathrm{MoC}$ catalysts for the conversion of $\mathrm{CO}_{2}$ : the metal/C ratio as a key factor defining activity, selectivity, and stability. $J$. Am. Chem. Soc. 138, 8269-8278. doi: 10.1021/jacs.6b04529

Posada-Perez, S., Viñes, F., Ramirez, P. J., Vidal, A. B., Rodriguez, J. A., and Illas, F. (2014). The bending machine: $\mathrm{CO}_{2}$ activation and hydrogenation on $\delta$ - $\mathrm{MoC}(001)$ and $\mathrm{B}-\mathrm{Mo}_{2} \mathrm{C}(001)$ surfaces. Phys. Chem. Chem. Phys. 16, 14912-14921. doi: 10.1039/C4CP01943A

Ren, J., Huo, C.-F., Wang, J., Chao, Z., Li, Y.-W., and Jiao, H. (2006). Density functional theory study into the adsorption of $\mathrm{CO}_{2}, \mathrm{H}$ and $\mathrm{CH}_{x}(x=$ $0-3)$ as well as $\mathrm{C}_{2} \mathrm{H}_{4}$ on $\alpha-\mathrm{Mo}_{2} \mathrm{C}\left(\begin{array}{llll}0 & 0 & 0 & 1\end{array}\right)$. Surf. Sci. 600, 2329-2337. doi: 10.1016/j.susc.2006.03.027

Rodriguez, J. A., Evans, J. E., Feria, L., Vidal, A. B., Liu, P., Nakamura, K., et al. (2013). $\mathrm{CO}_{2}$ hydrogenation on $\mathrm{Au} / \mathrm{TiC}, \mathrm{Cu} / \mathrm{TiC}$, and $\mathrm{Ni} / \mathrm{TiC}$ catalysts: production of CO, methanol, and methane. J. Catal. 307, 162-169. doi: 10.1016/j.jcat.2013.07.023 
Rodriguez, J. A., Feria, L., Jirsak, T., Takahashi, Y., Nakamura, K., and Illas, F. (2010). Role of $\mathrm{Au}-\mathrm{C}$ interactions on the catalytic activity of Au nanoparticles supported on $\mathrm{TiC}(001)$ toward molecular oxygen dissociation. J. Am. Chem. Soc. 132, 3177-3186. doi: 10.1021/ja910146g

Rodriguez, J. A., and Illas, F. (2012). Activation of noble metals on metal-carbide surfaces: novel catalysts for $\mathrm{CO}$ oxidation, desulfurization and hydrogenation reactions. Phys. Chem. Chem. Phys. 14, 427-438. doi: 10.1039/C1CP22738F

Rodriguez, J. A., Ramirez, P. J., Asara, G. G., Viñes, F., Evans, J., Liu, P., et al. (2014). Charge polarization at a $\mathrm{Au}-\mathrm{TiC}$ interface and the generation of highly active and selective catalysts for the low-temperature water-gas shift reaction. Angew. Chem. Int. Ed. 53, 11270-11274. doi: 10.1002/anie.201407208

Rodriguez, J. A., Viñes, F., Illas, F., Liu, P., Takahashi, Y., and Nakamura, K. (2007). Adsorption of gold on $\mathrm{TiC}(001)$ : Au-C interactions and charge polarization. J. Chem. Phys. 127:211102. doi: 10.1063/1.2814246

Si, R., Tao, J., Evans, J., Park, J.-B., Barrio, L., Hanson, J. C., et al. (2012). Effect of ceria on gold-titania catalysts for the water-gas shift reaction: fundamental studies for $\mathrm{Au} / \mathrm{CeO}_{\mathrm{x}} / \mathrm{TiO}_{2}(110)$ and $\mathrm{Au} / \mathrm{CeO}_{\mathrm{x}} / \mathrm{TiO}_{2}$ Powders J. Phys. Chem. C 116, 23547-23555. doi: 10.1021/jp3089325

Silvi, B., and Savin, A. (1994). Classification of chemical bonds based on topological analysis of electron localization functions. Nature 371, 683-686. doi: 10.1038/371683a0

Taifan, W., Boily, J.-F., and Balirusaitis, J. (2016). Surface chemistry of carbon dioxide revisited. Surf. Sci. Rep. 71, 595-671. doi: 10.1016/j.surfrep.2016.09.001

Vidal, A. A., Feria, L., Evans, J., Takahashi, Y., Liu, P., Nakamura, K., et al. (2012). $\mathrm{CO}_{2}$ activation and methanol synthesis on novel $\mathrm{Au} / \mathrm{TiC}$ and $\mathrm{Cu} / \mathrm{TiC}$ catalysts. J. Phys. Chem. Lett. 3, 2275-2280. doi: 10.1021/jz300989e
Xu, W., Ramirez, P. J., Stacchiola, D., and Rodriguez, J. A. (2014). Synthesis of $\alpha-\mathrm{MoC}_{1-\mathrm{x}}$ and $\beta-\mathrm{MoC}_{\mathrm{y}}$ catalysts for $\mathrm{CO}_{2}$ hydrogenation by thermal carburization of Mo-oxide in hydrocarbon and hydrogen mixtures. Catal. Lett. 144, 1418-1424. doi: 10.1007/s10562-014-1278-5

Yang, X.-F., Wang, A., Qiao, B., Li, J., Liu, J., and Zhang, T. (2013). Single-atom catalysts: a new frontier in heterogeneous catalysis. Acc. Chem. Res. 46, 1740-1748. doi: 10.1021/ar3 $00361 \mathrm{~m}$

Yao, S., Zhang, X., Zhou, W., Gao, R., Xu, W., Ye, Y., et al. (2017). Atomiclayered Au clusters on $\alpha-\mathrm{MoC}$ as catalysts for the low-temperature water-gas shift reaction. Science 357, 389-393. doi: 10.1126/science.aah4321

Zhang, X., Shi, H., and Xu, B.-Q. (2005). Catalysis by gold: isolated surface $\mathrm{Au}^{3+}$ ions are active sites for selective hydrogenation of 1,3-butadiene over $\mathrm{Au} / \mathrm{ZrO}_{2}$ catalysts. Angew. Chem. Int. Ed. 44, 7132-7135. doi: 10.1002/anie.2005 02101

Conflict of Interest: The author declares that the research was conducted in the absence of any commercial or financial relationships that could be construed as a potential conflict of interest.

Copyright $\odot 2020$ Rodriguez. This is an open-access article distributed under the terms of the Creative Commons Attribution License (CC BY). The use, distribution or reproduction in other forums is permitted, provided the original author $(s)$ and the copyright owner(s) are credited and that the original publication in this journal is cited, in accordance with accepted academic practice. No use, distribution or reproduction is permitted which does not comply with these terms. 